\title{
Renal-limited thrombotic microangiopathy after switching from bevacizumab to ramucirumab: a case report
}

\author{
Ryo Yamada', Takao Okawa ${ }^{1}$, Ken Matsuo ${ }^{1}$, Makoto Suzuki ${ }^{2}$, Noriko Mori ${ }^{1}$ and Kiyoshi Mori ${ }^{1,3^{*}}$ (D)
}

\begin{abstract}
Background: It is well known that vascular endothelial growth factor (VEGF) inhibitors can cause proteinuria. The incidence of proteinuria is high for bevacizumab, a humanized monoclonal antibody directed against VEGF, but the range of proteinuria rarely becomes nephrotic (2.2\% occurrence according to a meta-analysis). In such cases, renal pathology shows thrombotic microangiopathy (TMA). Ramucirumab, anti-VEGF receptor 2 (VEGFR2) monoclonal antibody, can also cause proteinuria, but it is not yet reported whether the drug may induce TMA.

Case presentation: Here, we report a case who immediately developed TMA by ramucirumab after multiple courses of bevacizumab treatment. This is the first case of pathologically-proved TMA by ramucirumab. After cessation of the drug, symptoms of TMA improved gradually.

Conclusions: This case demonstrates that not only blockade of VEGF but also VEGFR2 antagonism may result in TMA, which is a rare but life-threatening complication of cancer treatment drug.
\end{abstract}

Keywords: Bevacizumab, Nephrotic syndrome, Proteinuria, Ramucirumab, Thrombotic microangiopathy

\section{Background}

Vascular endothelial growth factor (VEGF) inhibitors are increasingly applied to treat a number of malignancies such as metastatic or recurrent colorectal, non-small cell lung, breast, and renal cell cancers. Bevacizumab, a humanized monoclonal antibody targeted against VEGF, is broadly used as the first- or second-line therapy to various malignancies [1]. The drug often causes proteinuria in treated patients [2], but it is rare bevacizumab-induced proteinuria reaches to a nephrotic range [3]. In such cases, renal pathology shows thrombotic microangiopathy (TMA) and, at the molecular level, inactivating VEGF signaling leads to damage of glomerular endothelial cells [4]. Other drugs, such as VEGF Trap (anti-VEGF ligand inhibitor) [5] or multi-tyrosine kinase inhibitors (including sunitinib, sorafenib and pazopanib) [6] may cause proteinuria and TMA.

\footnotetext{
* Correspondence: kiyoshimori2001@gmail.com

'Department of Nephrology, Shizuoka General Hospital, Shizuoka 420-8527, Japan

${ }^{3}$ Department of Nephrology and Kidney Research, Center for Public Health, Shizuoka General Hospital, Shizuoka 420-8527, Japan

Full list of author information is available at the end of the article
}

Ramucirumab, anti-VEGF receptor 2 (VEGFR2) monoclonal antibody, is approved for treating gastric, non-small-cell lung, and metastatic colorectal cancers as the second-line therapy. Ramucirumab also potentiates proteinuria [7], but it is unknown whether ramucirumab use is associated with development of TMA. Here, we report a case in which TMA occurred immediately after switching chemotherapy from bevacizumab to ramucirumab.

\section{Case presentation}

A 75-year-old woman was diagnosed as having stage IV transverse colon cancer in our hospital and began to receive chemotherapy in another hospital. As the first therapy, mFOLFOX6 (modified fluorouracil, leucovorin and oxaliplatin) plus bevacizumab (anti-VEGF-A antibody) was administered for 23 courses over 1 year with few side effects (Fig. 1). Since her cancer status was progressive disease after the above treatment, the secondary therapy, FOLFILI (fluorouracil, leucovorin and irinotecan) plus ramucirumab (anti-VEGFR2 antibody) was started. After 2 courses of therapy (on days 1 and 22), she gradually developed anasarca and nephrotic syndrome and was referred to our nephrology clinic. On

(c) The Author(s). 2019 Open Access This article is distributed under the terms of the Creative Commons Attribution 4.0 International License (http://creativecommons.org/licenses/by/4.0/), which permits unrestricted use, distribution, and 


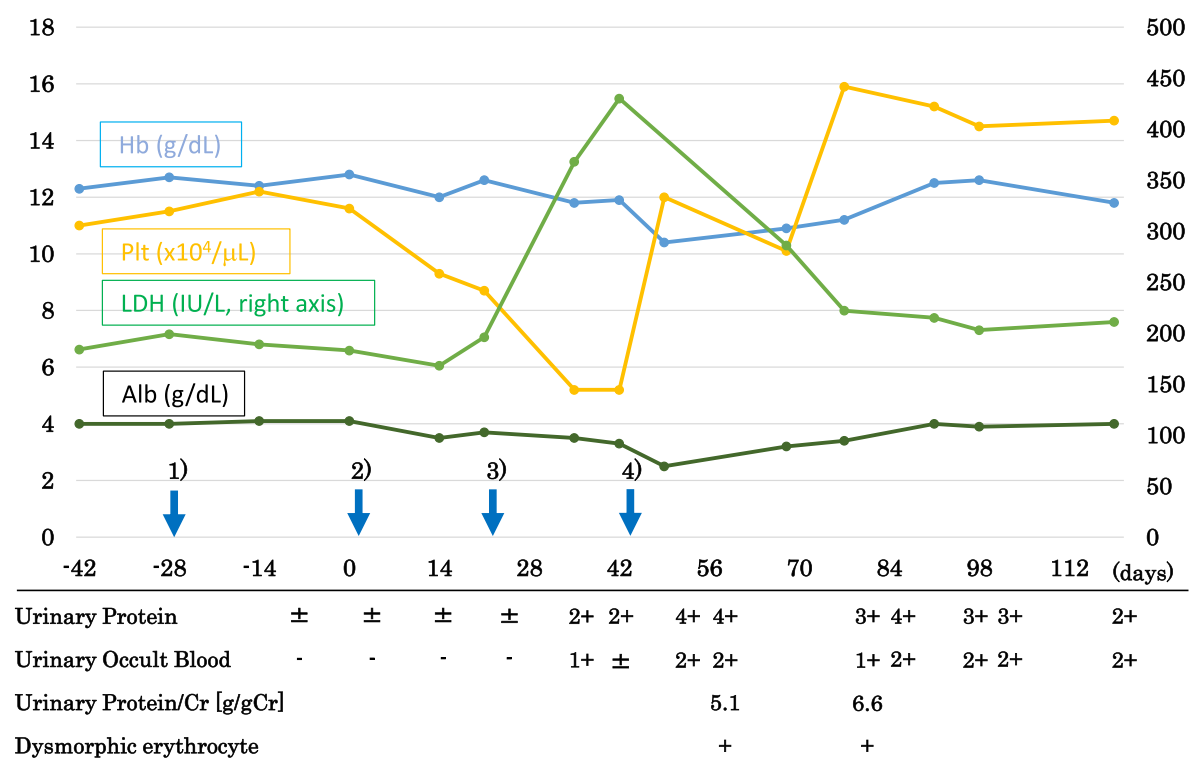

Fig. 1 The clinical course of the case. 1) The 23rd administration of the primary therapy (containing bevacizumab) on day - 28. 2) The first administration of the secondary therapy (containing ramucirumab) on day 1. 3) The second administration of the secondary therapy (containing ramucirumab) on day 22. 4) Renal biopsy on day 45

immediate admission on day 44, her blood test showed thrombocytopenia (platelets $57,000 / \mu \mathrm{L}$ ), slight normocytic anemia (hemoglobin $11.3 \mathrm{~g} / \mathrm{dL}$ ), mild hypoalbuminemia $(3.0 \mathrm{~g} / \mathrm{dL})$, and mild increase of lactate dehydrogenase level (433 IU/L) (Table 1). Schistocytes were not found on the peripheral blood smear. Haptoglobin level was not measured. Urinary protein was 5.1 g/g-creatinine and dysmorphic erythrocytes were found in the urine. Renal biopsy on day 45 showed fibrin thrombi within capillary loops, mesangiolysis and double contour of the basement membrane of glomeruli (Fig. 2 a, b, c). Immunofluorescence showed weak deposition of IgM, fibrinogen and $\mathrm{Clq}$ in mesangio-capillary regions (Fig. 2d). Electron micrograph showed diffuse endothelial swelling with obliteration of capillary lumina (Fig. 3).
Pathology was diagnosed as renal-limited TMA. Other causes of nephrotic syndrome, such as focal segmental glomerulosclerosis, membranous nephropathy and membranoproliferative glomerulonephritis, were denied. Ramucirumab was discontinued after the biopsy. By 6 weeks (day 69) after the last ramucirumab injection, thrombocytopenia $(101,000 / \mu \mathrm{L})$ and hypoalbuminemia $(3.2 \mathrm{~g} / \mathrm{dL})$ showed improvement.

\section{Discussion and conclusions}

It is well known that VEGF inhibitors, especially bevacizumab, can induce proteinuria and TMA [4]. A meta-analysis comprising 12,268 patients showed that bevacizumab use was associated with 13.3\% incidence of all-grade proteinuria [relative risk (RR) 2.8], 2.2\%

Table 1 Laboratory findings upon admission (on day 44)

\begin{tabular}{|c|c|c|c|c|c|}
\hline \multicolumn{4}{|l|}{ Blood test } & \multicolumn{2}{|l|}{ Jrine test } \\
\hline White blood cell & $3800 / \mu \mathrm{L}$ & C-reactive protein & $0.09 \mathrm{mg} / \mathrm{dL}$ & Gravity & 1.023 \\
\hline Neutrophil & $57.6 \%$ & $\lg G$ & $590 \mathrm{mg} / \mathrm{dL}$ & $\mathrm{pH}$ & 6.0 \\
\hline Lymphocyte & $29.3 \%$ & $\lg A$ & $125 \mathrm{mg} / \mathrm{dL}$ & Protein & $4+$ \\
\hline Hemoglobin & $11.3 \mathrm{~g} / \mathrm{dL}$ & $\lg M$ & $72 \mathrm{mg} / \mathrm{dL}$ & Occult blood & $3+$ \\
\hline Hematocrit & $33.7 \%$ & Complement 3 & $109 \mathrm{mg} / \mathrm{dL}$ & White blood cell & $0 / \mathrm{HPF}$ \\
\hline Platelet & $57,000 / \mu \mathrm{L}$ & Complement 4 & $18.8 \mathrm{mg} / \mathrm{dL}$ & Red blood cell & 10-19 /HPF \\
\hline Total protein & $5.7 \mathrm{~g} / \mathrm{dL}$ & $\mathrm{CH} 50$ & $47 \mathrm{IU} / \mathrm{mL}$ & Dysmorphic erythrocyte & + \\
\hline Albumin & $3.0 \mathrm{~g} / \mathrm{dL}$ & Hepatitis B s antigen & - & Protein & $941 \mathrm{mg} / \mathrm{dL}$ \\
\hline Blood urea nitrogen & $19 \mathrm{mg} / \mathrm{dL}$ & Hepatitis C virus antibody & - & Creatinine & $184 \mathrm{mg} / \mathrm{dL}$ \\
\hline Creatinine & $0.65 \mathrm{mg} / \mathrm{dL}$ & & & & \\
\hline
\end{tabular}



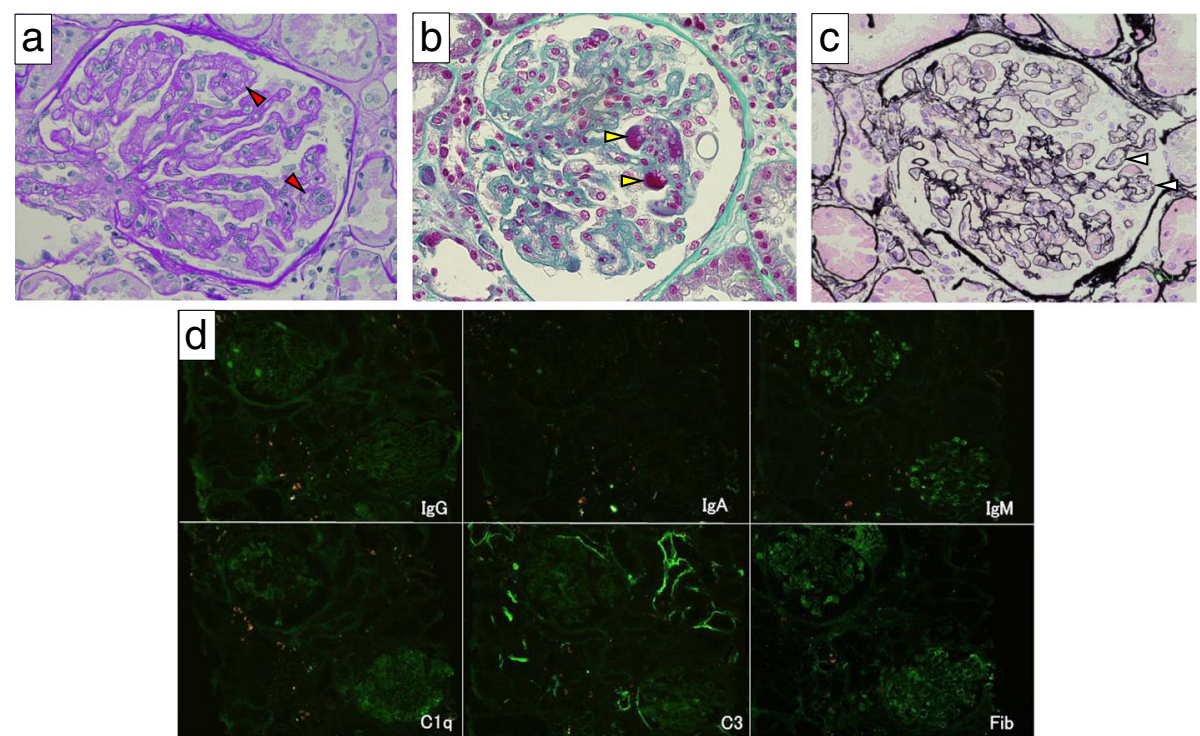

Fig. 2 Renal biopsy findings of the case. a Periodic acid-Schiff staining showing mesangiolysis (red arrowhead). Original magnification 40X. b Azan staining showing fibrin thrombi (yellow arrowhead). 40X. c Periodic acid-methenamine silver staining showing double contour of the basement membrane (white arrowhead). 40X. d Immunofluorescence for IgG, IgA, IgM, C1q, C3 and fibrinogen (Fib). 20X

incidence of grade 3 proteinuria $(\geq 3.5 \mathrm{~g} / 24 \mathrm{~h}$, RR 4.8$)$, and $0.8 \%$ incidence of nephrotic syndrome [3]. On the other hand, a recent meta-analysis of 4996 subjects revealed that ramucirumab treatment was associated with 9.4\% incidence of all-grade proteinuria (RR 3.4), 1.1\% incidence of grade 3 proteinuria (RR 8.3 ), and $0.04 \%$ incidence of nephrotic syndrome [7]. These findings suggest

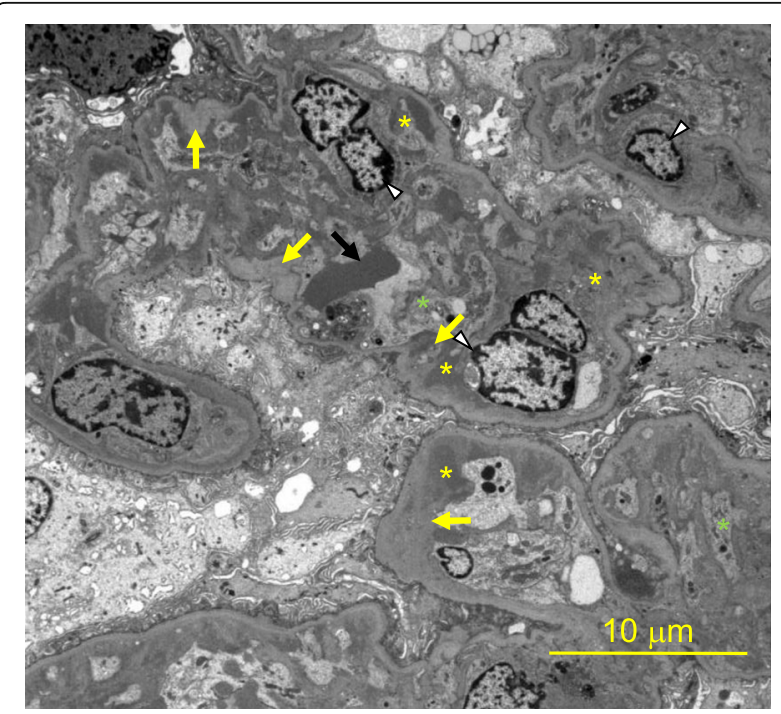

Fig. 3 Electron micrograph. Electroscopic imaging showed endothelial cell enlargement (white arrowhead), subendothelial swelling (yellow asterisk), diffuse mesangiolysis and obstruction of the capillary lumen (green asterisk), widening of the glomerular basement membrane (yellow arrow) and deformed erythrocyte (black arrow) that severe renal side effects may be less common in ramucirumab use compared to bevacizumab use.

The underlying mechanism of VEGF inhibitor-induced proteinuria is based upon a fact that a strict amount of VEGF expressed by podocytes is required to maintain the integrity of glomerular endothelial function and glomerular filtration barrier through VEGFR2 expressed upon endothelial cells $[3,4,8,9]$. The regulation of susceptibility to VEGF inhibition is not understood well, and it is unknown why a patient who tolerated long-term bevacizumab therapy developed TMA soon after switching to ramucirumab.

Double contour of the glomerular basement membrane is regarded as a chronic lesion [10]. Therefore, before administration of ramucirumab, repeated injection of bevacizumab may have already predisposed the glomeruli of the case presented here to develop nephrotic syndrome easily. Indeed, a recent work by our colleagues has shown that doubling in glomerular filtration of albumin causes only mild increase in albuminuria [11].

As to findings by immunofluorescence, the present case showed weak glomerular deposition of IgM, fibrinogen and $\mathrm{C1q}$, consistently with some cases in a previous report of VEGF inhibitor-induced TMA [6]. In that report, most cases showed renal dysfunction, but serum creatinine levels were less than $1 \mathrm{mg} / \mathrm{dl}$ in $20 \%$ of the cases. Of note, the current case exhibited normal renal function despite having severe occlusion of glomerular capillaries in some glomeruli of renal biopsy samples.

Cancer drug-induced TMA is divided into 2 distinct categories: types I and II [12]. Type I cancer 
drug-induced TMA develops dose-dependently, typically, at 6 months or later after starting therapy, and is usually permanent and irreversible (which may be caused by mitomycin $\mathrm{C}$, gemcitabine or oxaliplatin). It is usually associated with acute renal failure. The pathological finding is both arteriolar and glomerular capillary thrombosis. On the contrary, type II cancer drug-induced TMA is not dose-related, may occur any time after initiation of and in the course of treatment ( 1 dose to 29 months later), and has a high likelihood of recovery by stopping the drug (potentially caused by anti-VEGF agents). Glomerular capillary thrombosis lesions are exclusively found [12]. In our case, oxaliplatin was administered as the first therapy. It was considered that TMA was not caused by this drug, since she had relatively minor kidney failure and her renal pathology showed no arteriolar thrombosis. Therefore, we concluded that this case had type II cancer drug-induced TMA due to anti-VEGF agent(s) and it was clinically indicated that the culprit was ramucirumab. To our knowledge, this is the first biopsy report of ramucirumab-induced TMA.

In summary, we present a metastatic colorectal cancer patient who developed TMA after switching from bevacizumab to ramucirumab. Cessation of ramucirumab led to a gradual recovery from TMA. However, we cannot definitively exclude a possibility that previous treatments by bevacizumab and oxaliplatin had a causative or additional role.

\section{Abbreviations}

RR: Relative risk; TMA: Thrombotic microangiopathy; VEGF: Vascular endothelial growth factor; VEGFR2: Vascular endothelial growth factor receptor 2

\section{Acknowledgements}

We thank Dr. Hiroyuki Muro (Department of Pathology) for discussion.

\section{Funding}

No funding was obtained for this study.

\section{Availability of data and materials}

The dataset supporting the conclusions of this article is included within the article

\section{Authors' contributions}

RY, TO, KMatsuo, MS, NM, and KMori contributed to the data collection; RY and KMori designed the research. RY, KMatsuo, and MS evaluated the pathological tissue. RY performed primary manuscript preparation; RY and KMori wrote the paper. KMori has primary responsibility for the final content; and RY, TO, KMatsuo, MS, NM, and KMori reviewed the paper and revised it critically. All authors read and approved the final manuscript.

\section{Ethics approval and consent to participate}

A family of the participant signed a letter of informed consent to allow her data to be stored, as required by Shizuoka General Hospital.

\section{Consent for publication}

Written consent was obtained from a family of the patient for publication of this case report and any accompanying images. A copy of the written consent is available for review by the Editor of this journal.

\section{Competing interests}

The authors declare that they have no competing interests.

\section{Publisher's Note}

Springer Nature remains neutral with regard to jurisdictional claims in published maps and institutional affiliations.

\section{Author details}

'Department of Nephrology, Shizuoka General Hospital, Shizuoka 420-8527, Japan. ${ }^{2}$ Department of Pathology, Shizuoka General Hospital, Shizuoka 420-8527, Japan. ${ }^{3}$ Department of Nephrology and Kidney Research, Center for Public Health, Shizuoka General Hospital, Shizuoka 420-8527, Japan.

Received: 27 August 2018 Accepted: 21 December 2018 Published online: 11 January 2019

\section{References}

1. Ferrara N, Adamis AP. Ten years of anti-vascular endothelial growth factor therapy. Nat Rev Drug Discov. 2016;15(6):385-403.

2. Izzedine H, Rixe O, Billemont B, Baumelou A, Deray G. Angiogenesis inhibitor therapies: focus on kidney toxicity and hypertension. Am J Kidney Dis. 2007:50(2):203-18.

3. Wu S, Kim C, Baer L, Zhu X. Bevacizumab increases risk for severe proteinuria in cancer patients. J Am Soc Nephrol. 2010;21 (8):1381-9.

4. Eremina V, Jefferson JA, Kowalewska J, Hochster H, Haas M, Weisstuch J, Richardson C, Kopp JB, Kabir MG, Backx PH, Gerber HP, Ferrara N, Barisoni L, Alpers CE, Quaggin SE. VEGF inhibition and renal thrombotic microangiopathy. N Engl J Med. 2008;358(11):1129-36.

5. Izzedine H, Massard C, Spano JP, Goldwasser F, Khayat D, Soria JC. VEGF signalling inhibition-induced proteinuria: mechanisms, significance and management. Eur J Cancer. 2010;46(2):439-48.

6. Pfister F, Amann K, Daniel C, Klewer M, Buttner A, Buttner HM. Characteristic morphological changes in anti-VEGF therapy-induced glomerular microangiopathy. Histopathology. 2018;73(6):990-1001.

7. Arnold D, Fuchs CS, Tabernero J, Ohtsu A, Zhu AX, Garon EB, Mackey JR, Paz-Ares L, Baron AD, Okusaka T, Yoshino T, Yoon HH, Das M, Ferry D, Zhang Y, Lin Y, Binder P, Sashegyi A, Chau I. Meta-analysis of individual patient safety data from six randomized, placebo-controlled trials with the antiangiogenic VEGFR2-binding monoclonal antibody ramucirumab. Ann Oncol. 2017:28(12):2932-42.

8. Eremina V, Sood M, Haigh J, Nagy A, Lajoie G, Ferrara N, Gerber HP, Kikkawa Y, Miner JH, Quaggin SE. Glomerular-specific alterations of VEGF-A expression lead to distinct congenital and acquired renal diseases. J Clin Invest. 2003;111(5):707-16.

9. Sison K, Eremina V, Baelde H, Min W, Hirashima M, Fantus IG, Quaggin SE. Glomerular structure and function require paracrine, not autocrine, VEGFVEGFR-2 signaling. J Am Soc Nephrol. 2010;21(10):1691-701.

10. Vicky B, Katarina MW, David K. Thrombotic Microangiopathy and the kidney. Clin J Am Soc Nephrol. 2018;13(2):300-17.

11. Keita PM, Hideki Y, Masato K, Hirotaka I, Akira I, Takashige K, Kenichi K, Yukiko K, Naohiro T, Shoko O, Koichiro K, Tomomi E, Kazuwa N, Motoko Y, Masashi M, Kiyoshi M. Increase of Total nephron albumin filtration and reabsorption in diabetic nephropathy. J Am Soc Nephrol. 2017;28(1):278-89.

12. Izzedine H, Mark AP. Thrombotic microangiopathy, cancer, and cancer drugs. Am J Kidney Dis. 2015;66(5):857-68

Ready to submit your research? Choose BMC and benefit from

- fast, convenient online submission

- thorough peer review by experienced researchers in your field

- rapid publication on acceptance

- support for research data, including large and complex data types

- gold Open Access which fosters wider collaboration and increased citations

- maximum visibility for your research: over 100M website views per year

At BMC, research is always in progress.

Learn more biomedcentral.com/submission 